\title{
PENGEMBANGAN PEMBELAJARAN SENI BERBASIS AGAMA PADA ANAK USIA DINI
}

\author{
La Ode Anhusadar \\ IAIN Kendari \\ sadar.wanchines@gmail.com
}

\begin{abstract}
Abstrak
Pengembangan seni pada anak usia dini adalah salah satu proses pencapaian anak dalam bidang seni dengan berpatokan Standar Tingkat Pencapaian Perkembangan Anak Usia Dini. Melalui aktifitas seni, dapat meningkatkan daya cipta serta kreatifitas yang orisinil dan bersifat individual. Dan melalui aktivitas seni, anak dapat mengekspresikan diri. Pembelajaran sentra memberikan manfaat untuk mengembangkan rasa percaya diri anak. Mengembangkan potensi yang dimiliki oleh masing-masing individu. Karena menekankan pada bermain sambil belajar, memberikan pengalaman nyata bagi anak. Pelaksanaan pembelajaran seni berbasis agama terhadap peserta ajar bukan dilakukan secara impulsif, tetapi harus melalui bagian-bagian membuat rancangan pembelajaran, menyesuaikan tahapan perkembangan anak dan menyiapkan media pembelajaran. institut lembaga bagi peserta didik, diupayakan gum bisa mengoptimalkan perkembangan keinginan peserta didik terhadap aqidah. akar mana di dalam memberikan rangsangan pendidikan demi usaha membantu tumbuh dan kembangan badan dan biarawan peserta didik, metode kegiatan belajar mendidik diperlukan adanya petunjuk belajarnya untuk pembelajaran seni.
\end{abstract}

Kata Kunci : Pembelajaran Seni, Agama dan Sentra PAUD

\begin{abstract}
The development of art in early childhood is one of the processes of achieving children in the field of art based on the Standard Level of Achievement of Early Childhood Development. Through art activities can increase original creativity of individual. And through art activities, children can express themselves. The Sentra learning provides benefits for developing children's self-confidence. Developing the potential of each individual. Because it emphasizes playing while learning, providing a real experience for children. The implementation of religion-based art learning on students is not done spontaneously, but must go through the stages of making learning designs, adjusting stages of child development and preparing learning media. Educational institutions for early childhood are required to optimize the development of children's interest in religion. Which in providing educational stimuli as an effort to help the growth and physical and
\end{abstract}


spiritual development of children, the process of teaching and learning activities requires the existence of learning resources for art learning.

Keywords: Art Learning, Religion and Sentra of PAUD

\section{PENDAHULUAN}

Pembelajaran sentra adalah desain sentral yang diantaranya yaitu lembaga peserta didik, aturan belajar, desain belajar, belajar alam, desain belajarnya, dan desain lembaga. Cara pembelajaran sentra akan memfokuskan tutor disaat pembelajaran. Construction aktifitas pembelajaran sentra akan tercapai dilaksanakan di dalam ataupun di luar kelas, bermacam-macam kegiatan bermain dengan peralatan yang dibutuhkan berdasarkan tugas perkembangan merupakan arti dari sentra bermain (Ratina 2012). Sentra bermain bertujuan memberi luang kepada peserta didik untuk membudidayakan kemampuan, kesukaan dan keahlian. sentral bermain membuat anak bermain disertakan belajar mengasa rasa keindahan aktifitas bersama dengan beban untuk membangun diri sendiri. Pola aktifitas sentral seni meliputi keterampilan peserta didik untuk menggunting, melipat, mewarnai, mengelem membuat kerajinan yang berbedabeda (Intan and Subar 2017).

Anak akan meningkatkan keahlian motorik lembut, sinkronisasi lengan dan penglihatan, persepsi, ungkapan diri, dan estetic ketimbang efek sentral seni secara mandiri. Pendidikan Anak Usia Dini, ada dua kegiatan yang dikembangkan di sentra seni yaitu, seni musik dan seni kriya (Viatra and Triyanto 2014; Suci, Suhermin, and Triyonowati 2017; Lailan 2017). Sentra seni mengembangkan kemampuan motorik halus, kesesuaian gerak, nada dan aspek sosial emosional. Melalui aktifitas seni, akan meningkatkan daya cipta serta kreatifitas yang orisinil dan bersifat individual. Melalui aktivitas seni juga, anak dapat mengekspresikan diri(Suharto 2012; Sugiarto 2014). Sedangkan Emosi yang tidak dapat diekspresikan baik melalui verbal dapat dicurahkan anak melalui suatu karya seni, misalnya melalui lukisan, seni rupa, bernyanyi, menari dan sebagainya. Anak akan memiliki kemampuan untuk mengatur dan mengenali dirinya sendiri dalam proses pembelajaran(T. Wahyuni, Komarudin, and Anggoro 2019), Sehingga 


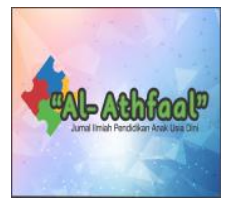

kepercayaan diri anak dapat meningkat dan potensi anak yang dimiliki berkembang secara optimal.

Pembelajaran sentra memberikan manfaat untuk mengembangkan rasa percaya diri anak(Risnawati 2012; Herlina 2017). Bermain sambil belajar memberikan pengalaman nyata bagi anak, karena dapat memenuhi kebutuhan anak untuk dapat mengeksplorasi lingkungan dan dapat menjawab rasa ingin tahu anak yang tinggi. Selain itu pembelajaran sentra dapat mengajarkan anak tanggung jawab dan meningkatkan keterampilan sosial. Karena peran Guru pada pembelajaran sentra sangatlah penting(Febriani 2016; Nurdyansyah 2018), yang sifatnya sebagai pengarah dan pembimbing atau inspirator yang tetap berfokus kepada Peserta didik. Melalui pembelajaran sentra, dapat pula menjadikan anak yang memiliki rentang fokus yang singkat menjadi ikut terlibat secara aktif mengikuti kegiatan sentra.

Pendekatan yang dilakukan dalam corak pembelajaran di penddikan kanak-kanak yaitu merupakan bagian dari Sentra, dengan arti lain pendekatan pembelajaran yang sistem pembalajarannya dilakukan dalam "lingkaran" (Circle) dan sentra bermain (Elyana 2017; Fadlillah 2018) dan ini arti dari pembelajaran sentra. Sentra biasanya dilaksanakan secara terpadu dengan "Saat Lingkaran" (Circle Time) yang lebih dikenal dengan "Sentra dan Saat Lingkaran" (Beyond Circlle Times and Centres BCCT).

Dorongan yang berpindah-pindah sesuai dengan tumbuh kembang yang diperoleh kanak yang dikasihkan sebagai dukungan untuk meraih tumbuh kembang yang lebih meningkat merupakan pengertian dari Pijakan (dukungan). Pendekatan penyelenggaraan pendidikan anak yang berpusat dalam operasi pembelajaran dari pendekatan Sentra menggunakan 4 ragam pijakan (scaffolding) untuk mendukung pekembangan anak, yaitu (1) dukungan sebelum pembelajaran, (2) dukungan lingkungan pembelajaran, (3) dukungann selama pembelajaran, (4) dukungan setelah pembelajaran(Munawaroh 2015; R. Wahyuni 2016; Fibriyanto 2016).

Pendekatan pembelajaran memfokuskan pokok yaitu titik pusat Kurikulum Balit bank Depdiknas, 2003-10-13 diantaranya; (1) belajar mengajar 
beradaptasi terhadap hakikat perkembangan anak. (2) beradaptasi terhadap keperluan anak. (3) belajar sembari bermain/ bermain sembari belajar. (4) Memakai pendekatan umum. (5) artistik dan terampil. (6) area mendukung. (7) meluaskan kecakapan berjiwa merupakan arti dari BCCT. Maka dari itu, diharapkan untuk anak diberikan kebebasan dalam mengembangkan kemampuan seninya. Beragam tentang keahlian yang dimiliki anak pada semua aspek tumbuh kembang, meliputi segi kadar agama serta moral, fisik dan motorik, psikologis, bercakap, sosial emosional, dan seninya.

\section{Tahap Perkembangan Seni}

\begin{tabular}{|c|c|}
\hline Usia & Tahapan \\
\hline 0-3 bulan & \multirow{4}{*}{$\begin{array}{l}\text { - } \text { Bisa membedakan antara bunyi dan suara. } \\
\text { - Menyukai macam suara atau musik } \\
\text { - Menyukai macam karya seni. }\end{array}$} \\
\hline 3-6 bulan & \\
\hline 6-9 bulan & \\
\hline 9-12 bulan & \\
\hline 12-18 Bulan & \multirow{2}{*}{$\begin{array}{l}\text { - } \text { Bisa membedakan antara bunyi dan suara-suara } \\
\text { - Tertarik dengan musik,irama, atau nada bicara tertentu. } \\
\text { - Menyukai terhadap pekerjaan seni serta mencoba } \\
\text { menghasilkan suatu gerakan yang menimbulkan suara }\end{array}$} \\
\hline 18-24 bulan & \\
\hline 2-3 Tahun & $\begin{array}{l}\text { - Anak bisa membedakan antara bunyi dan suara. } \\
\text { - Menyukai terhadapn kegiatan lagu, aksi orang, binatang } \\
\text { maupun tumbuhan } \\
\text { - Menyukai terhadap agenda/karya seninya }\end{array}$ \\
\hline 3-4 tahun & $\begin{array}{l}\text { - Anak bisa membandingkan dimana seperti apa bunyian } \\
\text { dan suaranya } \\
\text { - Menyukai terhadap kegiatan irama, aksi orang, fauna } \\
\text { ataupun flora } \\
\text { - Menyukai terhadap agenda/karya seninya }\end{array}$ \\
\hline 4-5 tahun & $\begin{array}{l}\text { - Anak bisa memanfaatkan bermacam alunan nada/musik } \\
\text { - Menyukai terhadap agenda seninya }\end{array}$ \\
\hline
\end{tabular}




\section{5-6 tahun $\quad$ • Anak bisa merasakan bermacam lantunan nada/bunyi \\ - Menyukai terhadap agenda seni}

\section{PEMBAHASAN}

Belahan otak bagian kanan anak berperan penting di dalam pendidikan seni untuk merangsang perkembangannya(Erfayliana 2016; Wathon 2016). Keberhasilan proses belajar mengajar ditentukan melalui interaksi antara pendidik dan peserta didik (Agustiana, Supriadi, and Komarudin 2019). Dalam meningkatkan kelincahan ekspresi anak, memahami segi kemanusiaan, peka serta berkonsentrasi yang luhur, serta kreatif yang cemerlang terbukti berpengaruh di pelajaran seni. Berbagai macam cara dalam menumbuhkembangkan keimanan atau kepercayaan serta taqwa anak kepada Allah SWT, diantaranya seperti pola pembelajaran sentra Imtaq (spiritual). Sentra Imtaq (spiritual) berperan penting terhadap tumbuh kembang anaknya, karena dalam penanaman spritual dan ketaqwaan pada anak adalah pondasi atau dasar yang kuat (Six 2017) serta sangat berguna dan penting keberadaannya dalam mendidik kepribadian anak yang baik untuk di masa 20-25 tahun mendatang.

Banyak teori ataupun orang-orang yang budiman berpendapat faktor agama serta adab adalah yang pertama dan harus membangun sebuah masyarakat yang teratur, damai serta aman, sebab sebuah peradaban akan menurun akhlak pada masyarkat. Salah satu tanggungjawab utama yang harus dilaksanakan oleh keluarga (orang tua) atau pendidik yaitu harus diabadikan serta diajarkan nilainilai keagamaan serta akhlak (moral) pada anak sejak kecil supaya terbentuknya karakter yang berderajat dan terbentuk sebuah tatanan dimasyarakat yang beradab(akhlak).

Sifat agama terhadap anak dibagi menjadi lima adalah Unreflective (rendah/minus apresiasi), egosentris, anthromortis, verbalis dan ritualis dan imitative. Mengenai bagian-bagian pendidikan agama dibagi menjadi 5 bagian bagian pendidikan keimanan, bagian pendidikan akhlak(moral), bagian pendidikan akliyah, bagian pendidikan sosial dan bagian pendidikanraga (Janna 2013; Khori 2016) 


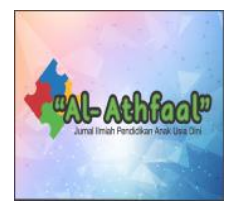

Pendidikan berkenaan dengan keimanan dan ketaatan anak sejak dini mengamati ajaran-ajaran dalam prosedur iman dan taqwa anak adalah (1) mengarahkan anak mengatakan lafaz Allah SWT. ia diajarkan aturan membaca kalimat keyakinan/tauhid. (2) Menumbuhkan mahaba dengan Allah SWT dan rasul-Nya sejak dini kepada anak. (3) Memberikan pengetahuan tentang al-Qur'an kepada anak sejak dini. (4) Mengajar anak dalam melaksanakan shalat. (5) mengajar anak agar berakhlak yang baik (Rodiawati and Komarudin 2018) dan etika Islam serta memberi pengertian hal yang dihalalkan dan diharamkan. Beberapa hal yang bisa meningkatkan keimanan serta ketaqwaananak sejak dini yang bisa dilakukan oleh guru/kedua orang tua adalah:

a. suritauladan yang baik.

Anak membutuhkan suritauladan yang baik atau contoh yang baik dari orangtua/pendidik. Diberikan tiruan secara langsung, tanpa memberikan teori karena masanya anak adalah masanya meniru orang dewasa. membaca basmalah sebelum sesudah melakuakn kegiatan.

b. Lagu-lagu Islami

Anak saat menyimak lagu yang cocok didalam suatu nada, lalu rohaninya serasa bahagia. Disarankan anak untuk mendengarkan musik Islamiyah

c. Doa(permintaan)

Seorang anak mampu memahami dan menghafalkan apa yang didengarkan dari gurunya/orangtuanya.

d. Pedoman(Al-Qur'an)

Saat anak telah usia 3 th, anak diajari membaca al-Fätihah, dan disaat usia 4 th anak diajari juz Amma. Usia 5 th anak mampu diajarkan menghafal/mengingat al-Qur'an (pendidikan hafiz Qur'an).

e. Tarih Islam/siroh nabawi

Tarih Islam/siroh nabawi, waliyullāh juga butuh untuk dkisahkan kepada anak, agar timbul di qolbu anak kecintaannya kepada Rasūlullāh, paranabi, asdiqoi, waliyullah maupun para shälihīn. Kanak-kanak menyenangi percakapan kisah karena daya ingatnya mereka luas dan karena kisah bisa digambarkan kejadian yang realita. 
f. beribadah

Anak kecil sifatnya meniru orang dewasa, seperti pelaksaan wudlu, shalat dan puasa akan ditiru oleh anak. Oleh karenanaya anak harus diajarkan kebiasaan dalam melaksanakan ibadah dari sejak dini.

1) Melatih terus cara berwudlu samapai anaknya paham, diajarkan dalam menyempurnakan berwudlu sejak ia umur 4 th serta haruslah ia diarahkan berwudhunya supaya biasa dalam melakukan untuk berwudhu sesuai dengan Al-Qur'an dan Hadits

2) Shalat, dalam melaksanakan shalat guru/orang tua haruslahlah di hadapan anak, mula-mula apa yang dilihat akan terpupuk di dalam pikiran anak. Anak usia 4 th akan merasakan gembira jika tegak sendiri dalam beribadah(sholat). Disaat usia 5 th diajarkannya surah al-fätihah serta usia 6 th diajarkannyaa juz amma serta meminta untuk membacanya setiap shalat

3) Bersedekah, anak dibiasakan memberi sedekah pada orang yang tidak punya apa-apa fakir yang mementingkan,salah satunya dalam memberi uang taupun material kepada orang yang membutuhan uang lalu meminta asupaya memberi pada orang yang tidak punya apa-apa (fakir) ataupun melatih sedekah dari uang miliknya seorang diri.

4) Firdaus. Sebagai orangtua/pendidik haruslah selalu mengingatkani anaknya dalam mengucapkan sesungguhnya Allah akan mengasihnya firdaus di tempat kebaikan yang sudah di perbuat,contohnya, Allah SWT akan mengasih firdaus kepada anak yang rajin melaksankan sholat, berbuat kebaikan, selalu apaadnaya(jujur), dan taat pada perintah Allah SWT dan larangannya.

\section{PENUTUP}

Pelaksanaan pembelajaran seni berbasis agama dengan anak didik bukanlah diberlakukan secara langsung, tetapi harus melewati bagian-bagian membuat rancangan pembelajaran, menyesuaikan tahapan perkembangan anak dan menyiapkan media pembelajaran. Pendidik (guru) memilah teknik yang cocok terhadap pembelajaran yang akan diberikan yaitu teknik pertunjukan yang telah dirancang selayaknya dengan tujuan agar anak-anak tak jenuh serta tak serasa 


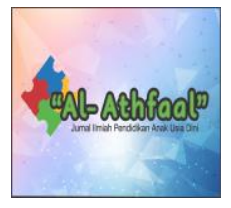

dipaksa dalam belajar suatu yang diberikan oleh pendidik pada peserta didik didalam agenda seni sebab dinggap bertambah efisien dan dapat diterima oleh anak dalam daya nalar anak-anak yang masih sangatterbatas.

Anak dituntut di Lembaga pendidikan bagi anak usia dini, agar bisa memaksimalkan perkembangan animo anak terhadap akidah. Dimana saat dalam memberi stimulus pendidikan seperti cara membantu tumbuhdankembang fisik dan biarawan anak, metode agenda belajarmengajar diperlukan adanya asal muasal belajar untuk pembelajaran seni. Peserta didik mampu menghasilkan informasi terkait terpada tema pelajaran yng sedang diajarkan dari berbagai asalmuasal belajar ini disebabkan oleh adanya asal muasal belajar. Yang dijadikan pedoman adalah buku asalmuasal belajar di sini tidak hanya diartikan sebagai dalam pembelajaran atau guru yang selalu memberikan materi saja, akantetapi asalmuasal belajar itu dibagi dalam beberapa formasi, yaitu bisa berupa informasi, manusia, benda mati, cara, serta area. dalam belbagai pola asamuasal belajar yang bisa digunakan serta ditata didalam agenda belajarmengajar pembelajaran seni, seorang pendidik diharapkan bisa meluaskan referensi dalambelajar. Semua ini tujuannya supaya bisa memperluas serta memudahkan peserta didik dalam menemukan referensi, serta dapat mengembangkan minat terhadap agamanya serta mampu mempunyai jiwanya aqidah yang baiknya kelak.

\section{Daftar Pustaka}

Agustiana, Nia, Nanang Supriadi, And Komarudin Komarudin. 2019. "Meningkatkan Kemampuan Penalaran Matematis Dengan Penerapan Pendekatan Bridging Analogy Ditinjau Dari Self-Efficacy." Inovasi Pembangunan: Jurnal Kelitbangan 7 (1): 61-61.

Elyana, Luluk. 2017. "Peran Self Regulated Learning Dalam Pembelajaran Paud." Prosiding Teтu Ilmiah Nasional X Ikatan Psikologi Perkembangan Indonesia 1. 


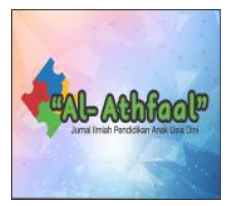

Erfayliana, Yudesta. 2016. "Aktivitas Bermain Dan Perkembangan Jasmani Anak." Terampil: Jurnal Pendidikan Dan Pembelajaran Dasar 3 (1): $145-58$.

Fadlillah, Mohammad. 2018. "Persepsi Mahasiswa Pg-Paud Universitas Muhammadiyah Ponorogo Terhadap Paud Di Kabupaten Ponorogo." Jurnal Obsesi: Jurnal Pendidikan Anak Usia Dini 2 (1): 118-23.

Febriani, Efri. 2016. "Upaya Meningkatkan Pengembangan Motorik Kasar (Melompat) Anak Melalui Permainan Lompat Tali Pada Kelompok B Tk Al-Hidayah Palaosan Tahun Pelajaran 2015-2016." Prosiding Ilmu Pendidikan 1 (2).

Fibriyanto, Agus. 2016. "Implementai Model Pendekatan Sentra Dan Saat Lingkaran Pada Sentra Agama Dalam Meningkatkan Kecerdasan Interpersonal Anak Didik (Studi Kasus Di Kbit La Tansa Cangkring Karanganyar Demak Tahun Pelajaran 2015/2016).” Stain Kudus.

Herlina, Elin. 2017. "Pendidikan Dan Pelatihan Dalam Meningkatkan Model Kerjasama Usaha Menengah Kecil Dan Mikro Dengan Usaha Besar Di Kecamatan Cikoneng Kabupaten Ciamis." Jurnal Ekonologi Ilmu Manajemen 1 (1): 71-81.

Intan, Pratiwi, And Junanto Subar. 2017. "Implementasi Penggunaan Alat Permainan Edukatif Di Sentra Kreativitas Kelompok TK B Di TK Taqiyya Ngadirejo Kartasura Tahun Pelajaran 2016/2017.” IAIN Surakarta.

Janna, Sitti Riadil. 2013. "Konsep Pendidikan Anak Dalam Perspektif Al-Ghazali (Implikasinya Dalam Pendidikan Agama Islam).” Al-Ta'dib 6 (2): 41-55.

Khori, Ahmad. 2016. "Manajemen Strategik Dan Mutu Pendidikan Islam." Manageria: Jurnal Manajemen Pendidikan Islam 1. 
Lailan, Alfina. 2017. "Model Pembelajaran Sentra Pendidikan Anak Usia Dini." An-Nahdhah 10 (2): 191-202.

Munawaroh, Dewi. 2015. "Pelaksanaan Model Sentra Dan Lingkaran Dalam Kegiatan Main Anak Usia Dini Di Kelompok Bermain Rumah Ibu Jongkang Sariharjo Ngaglik Sleman Yogyakarta." E-Jurnal Skripsi Mahasiswa Tp 4 (1).

Nurdyansyah, Nurdyansyah. 2018. "Model Pembelajaran Berbasis Masalah Pada Pelajaran Ipa Materi Komponen Ekosistem." Universitas Muhammadiyah Sidoarjo.

Ratina, Mahyumi. 2012. "Pembelajaran Agama Di Sentra Iman Dan Taqwa Taman Kanak-Kanak Huffazh Payakumbuh.” Jurnal Ilmiah Pesona Paud $1(5)$.

Risnawati, Vivit. 2012. "Optimalisasi Pendidikan Karakter Anak Usia Dini Melalui Sentra Main Peran Taman Kanak-Kanak Padang.” Jurnal Ilmiah Pesona Paud 1 (2).

Rodiawati, Heni, And Komarudin Komarudin. 2018. "Pengembangan E-Learning Melalui Modul Interaktif Berbasis Learning Content Development System.” Jurnal Tatsqif 16 (2): 172-85.

Six, All. 2017. "Back Issue Of Mudarrisa Volume 4 Issue 1.” Mudarrisa: Jurnal Kajian Pendidikan Islam 4 (1): 1-158.

Suci, Rahayu Puji, Suhermin Suhermin, And Triyonowati Triyonowati. 2017. "Peningkatan Kualitas Pendidikan Anak Usia Dini Melalui Penyediaan Sarana Penunjang Proses Pembelajaran Pada Pos Paud Di Kelurahan Merjosari Malang.” Jurnal Inspirasi Pendidikan 7 (1): 52-65. 


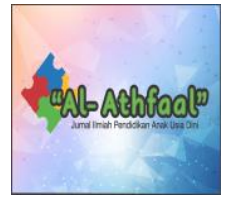

Sugiarto, Eko. 2014. "Ekspresi Visual Anak: Representasi Interaksi Anak Dengan Lingkungan Dalam Konteks Ekologi Budaya.” Mimbar Sekolah Dasar 1 (1): $1-6$.

Suharto, S. 2012. "Problematika Pelaksanaan Pendidikan Seni Musik Di Sekolah Kejuruan Non Seni." Harmonia: Journal Of Arts Research And Education $12(1)$.

Viatra, Aji Windu, And Slamet Triyanto. 2014. "Seni Kerajinan Songket Kampoeng Tenundi Indralaya, Palembang." Ekspresi Seni: Jurnal Ilmu Pengetahuan Dan Karya Seni 16 (2): 168-83.

Wahyuni, Rini. 2016. "Keterampilan Sains Anak Usia 4-5 Tahun Dalam Pembelajaranberbasis Sentra Dan Lingkaran Di Tk Andika Kota Cilegon Banten.” Jurnal Penelitian Dan Pengembangan Pendidikan Anak Usia Dini 3 (1): 27-38.

Wahyuni, Tri, Komarudin Komarudin, and Bambang Sri Anggoro. 2019. "Pemahaman Konsep Matematis Melalui Model Wee Dengan Strategi Qsh Ditinjau Dari Self Regulation." Aksioma: Jurnal Program Studi Pendidikan Matematika 8 (1).

Wathon, Aminul. 2016. "Neurosains Dalam Pendidikan.” Jurnal Lentera: Kajian Keagamaan, Keilmuan Dan Teknologi 1 (2): 284-94. 